\title{
The forkhead-box family of transcription factors: key molecular players in colorectal cancer pathogenesis
}

\author{
Paul Laissue(0)
}

\begin{abstract}
Colorectal cancer $(C R C)$ is the third most commonly occurring cancer worldwide and the fourth most frequent cause of death having an oncological origin. It has been found that transcription factors (TF) dysregulation, leading to the significant expression modifications of genes, is a widely distributed phenomenon regarding human malignant neoplasias. These changes are key determinants regarding tumour's behaviour as they contribute to cell differentiation/proliferation, migration and metastasis, as well as resistance to chemotherapeutic agents. The forkhead box (FOX) transcription factor family consists of an evolutionarily conserved group of transcriptional regulators engaged in numerous functions during development and adult life. Their dysfunction has been associated with human diseases. Several FOX gene subgroup transcriptional disturbances, affecting numerous complex molecular cascades, have been linked to a wide range of cancer types highlighting their potential usefulness as molecular biomarkers. At least 14 FOX subgroups have been related to CRC pathogenesis, thereby underlining their role for diagnosis, prognosis and treatment purposes.

This manuscript aims to provide, for the first time, a comprehensive review of FOX genes' roles during CRC pathogenesis. The molecular and functional characteristics of most relevant FOX molecules (FOXO, FOXM1, FOXP3) have been described within the context of CRC biology, including their usefulness regarding diagnosis and prognosis. Potential CRC therapeutics (including genome-editing approaches) involving FOX regulation have also been included. Taken together, the information provided here should enable a better understanding of FOX genes' function in CRC pathogenesis for basic science researchers and clinicians.
\end{abstract}

Keywords: Colorectal cancer, Forkhead transcription factors, Molecular aetiology

\section{Background}

Colorectal cancer $(\mathrm{CRC})$ is a public health concern as it accounts for over $9 \%$ of all cancer incidence, representing $>1.4$ million of new cases per year $[1,2]$. It is the third most commonly occurring cancer worldwide and the fourth most frequent cause of death having an oncological origin [3]. Several risk factors have been related to CRC, such as inflammatory bowel disease, antecedents of CRC in first-degree relatives, increased body mass index, cigarette smoking, little physical activity and particular dietary habits [4]. Adenomas of the colon, which can be conventional adenomas or sessile serrated polyps, are the

Correspondence: paul.laissue@urosario.edu.co

Center For Research in Genetics and Genomics-CIGGUR, GENIUROS Research Group, School of Medicine and Health Sciences, Universidad del Rosario, Carrera 24 N 63C-69, Bogotá, Colombia precursor lesions leading to most cases of CRC [5]. CRC has to be considered a complex disease resulting from a combination of environmental factors, genetic/epigenetic predisposing variants and specific molecular mechanisms. Three molecular pathways have been defined as major factors contributing to CRC carcinogenesis: microsatellite instability (MSI), chromosomal instability (CIN) and the CpG island methylator phenotype (CIMP) [6, 7].

The dysfunction of several genes in sporadic and familial cases has been associated with the disease's aetiology, such as KRAS, BRAF, c-Src, c-Myc, APC, TP53, PIK3CA, MSH2, MLH1, STK11, MSH6, PMS2, APC, CACNA1G, CDKN2A, IGF2, NEUROG1, RUNX3 and SOCS1 $[8,9]$. Some of these are currently used as clinically useful prognostic and therapeutic biomarkers [10]; indeed, since CRC development may take years, its early

(c) The Author(s). 2019 Open Access This article is distributed under the terms of the Creative Commons Attribution 4.0 International License (http://creativecommons.org/licenses/by/4.0/), which permits unrestricted use, distribution, and 
detection and the use of biochemical and molecular/ genetic diagnostic tools is a keystone for improving survival rates.

The evolution of omics sciences' experimental procedures during the last few years has led to new cancer classifications based on particular molecular findings underlying tumour's biology [11-13]. For instance, immune-MSI, canonical-CMS2, metabolic-CMS3 and mesenchymal-CMS4 CRC subtypes have been proposed based on transcriptomic differences between tumours which should improve the disease's diagnosis/prognosis/ treatment. Interestingly, it has been found that transcription factor (TF) dysregulation, mainly due to chromosomal deletion/translocation/amplification and point mutations, is a widely distributed phenomenon regarding human malignant neoplasias [14-16]. TF dysregulation can lead to the significant expression modifications of genes involved in various complex biological processes, such as cell identity determination, proliferation regulation and cell signalling for controlling machinery in response to micro-environmental signals [17]. These changes are key determinants regarding tumour's behaviour as they contribute to cell differentiation/proliferation, migration and metastasis, as well as resistance to chemotherapeutic agents.

Since the first association was made between DNA regulatory regions and phenotypic variation in bacteria, considerable efforts and advances have been made to understand TFs' genomic regulation, such as reporting new gene families, identifying genetic and epigenetic molecular modulatory mechanisms, describing expression profiles and programmes regarding numerous cell types, studying the evolution of genetic networks, developing omics data analysis and characterising variations on regulatory motifs and TF mutations in human disease-related encoding regions [15, 18-31]. TFs have been classically organised into families and subfamilies, depending on the sequence/structure of their DNA binding domain (DBD) [29]. The total amount of TFs has not yet been precisely stated; however, at least 1400 have high confidence sequence-specific DBD [20]. Mechanistically TFs recognise 6-12 bp-long DNA sequences located on target gene promoters/enhancers to regulate expression. These motifs, known as transcription factor binding sites (TFBS), provide specificity for binding and their occupancy has been related to several variables such as quantity, affinity and availability of regulatory complexes in specific regions $[28,32]$. TFs bind to other proteins (e.g. cofactors) to form macromolecular complexes which are essential elements for specific binding to TFBS and establishing complex regulatory networks [33-35].

The forkhead box (FOX) transcription factor family consists of an evolutionarily conserved group of transcriptional regulators engaged in numerous functions during development and adult life; their dysfunction has been associated with human diseases [36-42]. Several FOX gene subgroup transcriptional disturbances, affecting numerous complex molecular cascades, have been linked to a wide range of cancer types highlighting their potential usefulness as molecular biomarkers [23, 41-49]. At least 14 FOX subgroups have been related to CRC pathogenesis, thereby underlining their role for diagnosis, prognosis and treatment purposes.

This manuscript aims to provide, for the first time, a comprehensive review of FOX genes' roles during CRC pathogenesis. The molecular and functional characteristics of most relevant FOX molecules have been described within the context of CRC biology, including their usefulness regarding diagnosis and prognosis. Potential CRC therapeutics (including genome-editing approaches) involving FOX regulation have also been included. Taken together, the information provided here should enable a better understanding of FOX genes' function in CRC pathogenesis for basic science researchers and clinicians.

\section{Main text}

The FOX family of transcription factors: an overview

The first report of a FOX gene was published in the late 1980s when a mutant model of Drosophila melanogaster was described as having a transformation of the foregut resembling a head-like structure $[50,51]$. Since then, at least 50 additional members, which have been classified in 19 subgroups (FOXA to FOXS), have been discovered in human species [37, 40, 52-54]. All FOX members share a highly conserved $\sim 100$ residue DBD (the forkhead domain, FOX-DBD) which was first identified in Drosophila forkhead and mammalian HNF-3a (FOXA1), HNF-3b (FOXA2), HNF-3c (FOXA3) proteins [50, 52, 55]. The FOX-DBD binds to a target genes' core sequence $\left(5^{\prime}-(\mathrm{G} / \mathrm{A})(\mathrm{T} / \mathrm{C})(\mathrm{A} / \mathrm{C}) \mathrm{AA}(\mathrm{C} / \mathrm{T}) \mathrm{A}-3^{\prime}\right)$ located on the promoter regions [38]. Sequences adjacent to the core TFBS are also important for TF differential affinity and functions [56-58]. Structurally, the FOX-DBD consists of three $\mathrm{N}$-ter $\alpha$-helices, three $\beta$-strands and two loops, resembling butterfly wings or a "winged helix" [38, 59, 60]. However, some FOX-DBD have some modifications in their secondary structure composition and topological arrangements [60] (and references therein). It has been shown that the wings contribute to regulating DNA binding specificity and affinity [61].

Several post-translational modifications, such as phosphorylation, acetylation and ubiquitination, have been described which contribute to modulating different FOX proteins' functions, including their DNA-binding affinity [60]. Functional regions in addition to the DBD have 
been mapped for some FOX proteins, such as the FOXO subfamily, i.e. the transactivation domain (TAD), the nuclear localisation sequence (NLS) and the nuclear export sequence (NES) (Fig. 1). Contrary to the DBD, such regions are poorly conserved and may contain variable length homopolymeric tracts (e.g. Ala, Gln, Pro residues). In some cases (FOXL2, FOXP2) these regions' length can be modified above/below a threshold leading to cellular dysfunctions contributing to causing the disease [62-64]. To date, the Protein Data Bank-DBD contains the structure of the FOX-DBD bound to the DNA of several FOX members: FOXA1, FOXA2, FOXM1, FOXN1, FOXO1, FOXO2, FOXO4, FOXK1, FOXK2, FOXP1, FOXP2 and FOXP3 [65] (https://www.rcsb.org/).

FOX proteins are widely distributed throughout multiple species from yeasts to humans and play pleiotropic roles in developmental and adult age biological/cellular processes, such as cell cycle control, cell differentiation and proliferation, tissue homeostasis, aging, metabolism regulation and stress tolerance. FOX factors are key regulators of various signalling pathways regarding physiological and pathological conditions: phosphatidylinositol 3-kinase/protein kinase B (PI3K-AKT), transforming growth factor beta (TGF- $\beta$ ), WNT/ $\beta$-catenin, insulin, Sonic-Hedgehog and Jagged-Notch [38] (and references therein). FOX gene deregulation in cancer pathophysiology brings consequences regarding its onset, maintenance, progression and drug resistance. FOX molecules constitute therefore molecular biomarkers for diagnostic and prognostic purposes. Furthermore, they form coherent potential targets for therapeutic approaches, including genome editing-based strategies.

\section{A dual role for FOXOs as tumour suppressors and potential oncogenic proteins}

The FOXO subfamily of forkhead transcription factors, which has been widely studied during last 20 years, consists of four members in mammals: FOXO1, FOXO3A, FOXO4 and FOXO6. Structurally, these proteins include the forkhead (FKH) and TAD domains and nuclear localisation and exports signals [42, 66] (Fig. 1). All FOXO proteins have high FKH domain homology, particularly in the N-ter region (RXRSCTWPL motif) [40]. Concerning target DNA regions, FOXO proteins recognise the Daf-16 family member binding element ( $5^{\prime}$-GTAAA(T/ C)AA-3') and the insulin-responsive element $\left(5^{\prime}-(\mathrm{C} /\right.$ $\left.\mathrm{A})(\mathrm{A} / \mathrm{C}) \mathrm{AAA}(\mathrm{C} / \mathrm{T}) \mathrm{AA}-3^{\prime}\right)$ for regulating gene expression [67]. FOXO molecules are expressed in numerous tissues during embryo development and adult life, and have been related to different functions such as cell differentiation/proliferation, controlling metabolism, immunity, apoptosis, detoxification, DNA damage repair, cell cycle arrest, autophagy, homeostasis maintenance, modulating stress resistance and aging [39, 42, 68-76].

Upstream regulation of FOXO subfamily members has been well documented, especially the mechanism involving the phosphoinositide-3-kinase-protein kinase $\mathrm{B}$ (AKT) (PI3K-AKT) molecular cascade in response to insulin and growth factor stimulation $[69,77]$ FOXOs phosphorylation by AKT (on $\mathrm{Thr}^{32}, \mathrm{Ser}^{253}$ and $\mathrm{Ser}^{315}$ residues) enables its binding to 14-3-3 proteins; the complex so formed is then translocated from the nucleus to the cytoplasm [78] (Fig. 2). In addition to AKT, other kinases (e.g. SGK, IKK, ERK) are negative regulators of FOXO, while JNK and MST1 are able to activate it $[79,80]$.

Regarding cancer biology, FOXO proteins acts downstream of several oncogenic pathways such as, PI3KAKT, ERK and NF- $\mathrm{kB}-\mathrm{IKK} \beta$ (nuclear factor- $\mathrm{kB}$ and NF- $\mathrm{KB}$ kinase- $\beta$ inhibitor, respectively) [39, 77, 81-83]. FOXOs have mostly been described as tumour suppressors as they possess anti-proliferative and pro-apoptotic properties. FOXOs' anti-tumour function has been related to the regulation of key genes participating in cell death and cell cycle arrest, such as $p 27^{K I P 1}$, CDKN1A/ p21, FasL, Trail and Bim [80, 84, 85]. FOXOs are also involved in other complex networks, including numerous genes regulating the relevant process of tumorigenesis, such as oncogene-induced senescence, angiogenesis, invasiveness, oxidative stress regulation and interaction with other suppressors (e.g. p53).

A dual yet paradoxical role has been described for FOXO in CRC, as they can act as a cancer suppressor

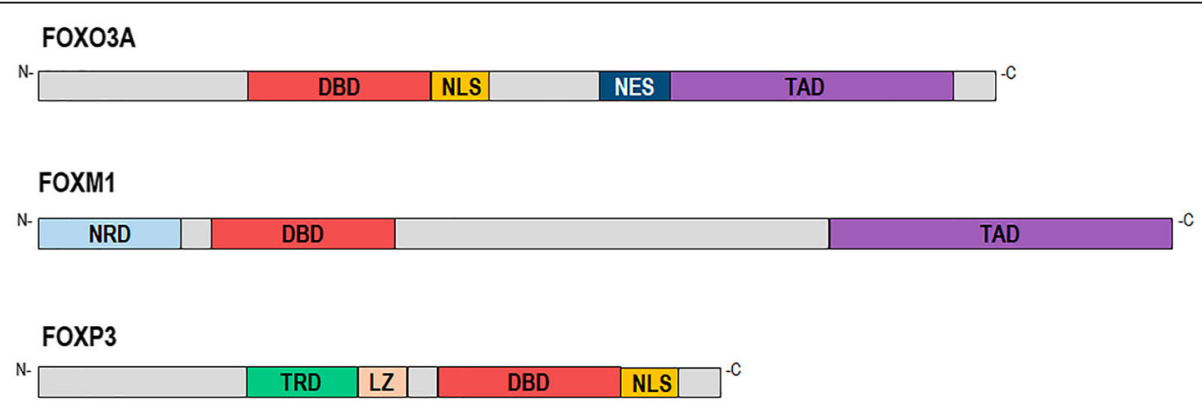

Fig. 1 Structure of FOXO3A, FOXM1 and FOXP3 proteins. DBD: DNA binding domain (forkhead domain); NLS: nuclear localisation sequence; NES: nuclear export sequence; TAD: transactivation domain; NRD: negative-regulatory domain; TRD: transcriptional repressor domain; LZ: leucine zipper motif 
genes or an oncogenes (see below). It has been shown, in colon carcinoma-derived cells, that the FOXO system activation/inhibition via gene overexpression/silencing or the pharmacological perturbation of several signalling pathways (PI3K-AKT, Wnt, $\beta$-catenin, EGFR) lead to CRC cancerogenesis [86-115].

Numerous studies have described FOXO participation in regulating the PI3K/AKT molecular cascade, a signalling pathway which becomes altered in most human cancers (Fig. 2). The PI3K is a family of lipid kinases involved in several key cellular processes such as differentiation, proliferation/growth, survival, metabolism and migration [116] (and references therein). This pathway is associated with different nodes constituted by numerous molecules, underlining different functions and having particular regulatory complexity. The PI3K pathway can be activated by different types of signal, including receptor tyrosine kinases (RTKs) and G-protein-coupled receptors and oncogenes leading to plasma membrane recruitment and the activation of class I PI3K family proteins [117]. PI3K activity enables AKT membrane recruitment; thereafter, AKT becomes activated, in turn, leading to the phosphorylation of different effectors, such as FOXOs, GSK3, eNOS, TSC2, BAD and p27. It has been shown that AKT activation induces FOXO3 accumulation in the cytoplasm via 14-3-3 protein action, thereby inhibiting its function [81, 118] (Fig. 2).
Several reports have studied the effect of FOXO activation/inactivation on CRC biology. Ericson et al. [111] used target homologous recombination in CRC cells to inactivate the AKT1, AKT2 or PDPK1 genes. The Akt1/ Akt2 double $\mathrm{KO}$, which was related to a substantial decrease in FOXO1A and FOXO3A phosphorylation, led to considerably reduced cell proliferation in vitro and perturbed metastasis in mice. The results suggested that the expression of genes, secondary to phosphorylated FOXO proteins' decreased activity in the nucleus, contributed to AKT factors' growth-promoting function. This effect appeared to be independent of other important PI3K signalling pathway molecules, such as mammalian target of rapamycin (mTOR) and glycogen synthase kinase 3 beta (GSK3 $\beta$ ).

Depletion of the PI3K regulatory subunit $\mathrm{p} 85 \alpha$ via siRNA transfection in LoVo and SW480 colorectal cell lines inhibited cell proliferation, induced G1 phase cell cycle arrest and sensitised colorectal cancer cells to 5-FU-induced apoptosis [112]. The lack of p85 $\alpha$ in these experiments led to a strong decrease in AKT (and phosphorylated AKT) which led to a significant decrease of FOXO proteins (FOXO1, FOXO3A and FOXO4) in the cytoplasmic compartment. A logical accumulation of these factors was observed in the nucleus which was related to some target genes' expression modification (e.g. cyclin D1 and cdk4 were downregulated while p27/Kip1

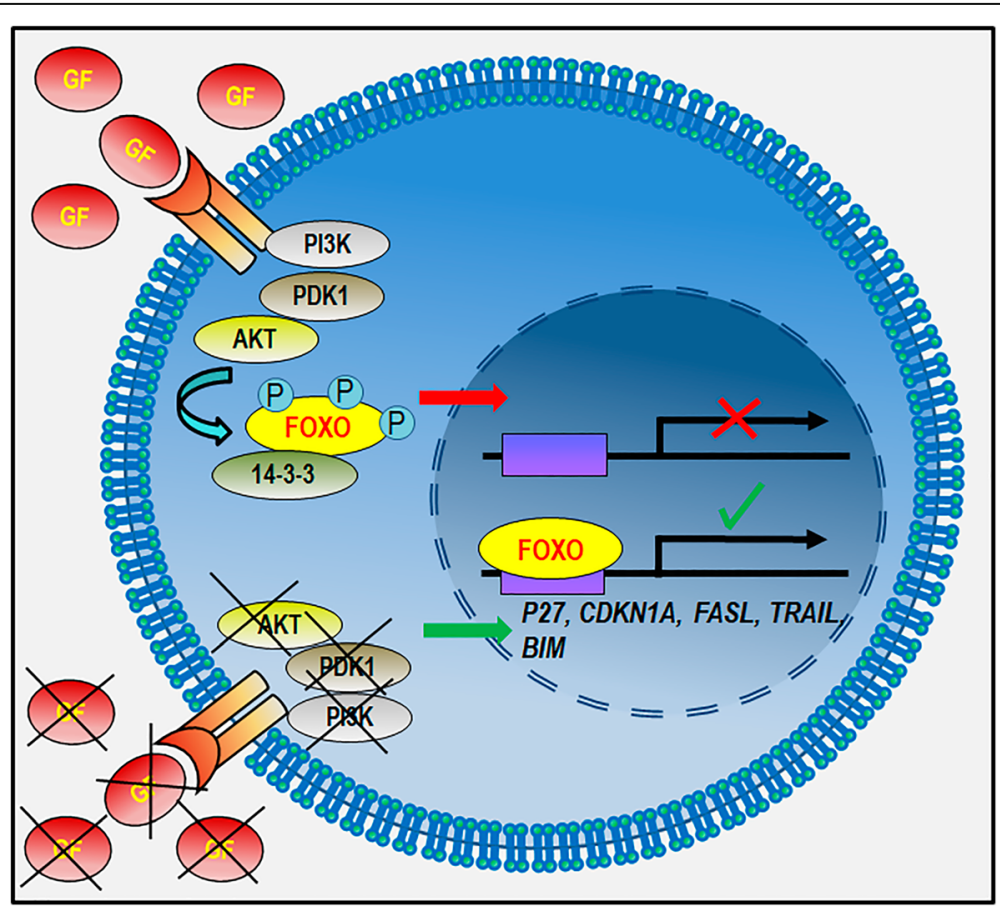

Fig. 2 Regulation of FOXO subcellular distribution and activity via PI3K/AKT activation. In the presence of growth factors the PI3K/AKT system is activated and the FOXO-TFs are phosphorylated. This modification creates a docking site for 14-3-3, which excludes FOXOs from the nucleus inhibiting the transactivation of target gene promoters (red arrow). In the contrary, the absence of growth factors and AKT/PI3K activation allows FOXO nuclear translocation and the transactivation of target gene promoters (green arrow). GF: growth factors 
and FasL were upregulated). Seminal work by Tenbaum et al., studied the crosstalk between WNT- $\beta$-catenin and PI3K-AKT-FOXO3A pathways in CRC tumorigenesis [115]. The authors explored the simultaneous effect of WNT- $\beta$-catenin molecule hyper-activation and PI3K-AKT inhibition on CRC biology. This scenario was related to FOXO3A and $\beta$-catenin nuclear accumulation, in turn, being related to a cell scattering phenotype and metastasis. It has been defined that FOXO3A and $\beta$-catenin regulate many metastasis-relevant genes, such as IQGAP2, CYR61, CLDN1, CAV1, EDN1 and KIT. Indeed, various metastasis-related biological processes are modulated (via target genes) by FOXO3A and $\beta$-catenin, such as cell motility and migration, angiogenesis, immune system evasion and cytoskeleton reorganisation. Nuclear $\beta$-catenin resistance to FOXO3A-mediated apoptosis has been induced by PI3K and AKT inhibitors in primary CRC cells. Interestingly, high FOXO3A and $\beta$-catenin nuclear concentrations have been related to the CRC metastatic stage and affected patients' shorter survival times [115]. Contrary to that reported by others, these findings add information regarding FOXO3A's potential oncogenic nature.

Shoeb et al. [90] have shown that aldose reductase inhibition, via PI3K/AKT, modulated FOXO3A activation in CRC cells, in turn, participating in sensitising tumour cells to tumour necrosis factor -TNF-related apoptosisinducing ligand (TRAIL)-induced apoptosis. Several other studies have described the effect of FOXO accumulation in the nucleus of CRC cells, some of which were based on using different kinds of molecules. For instance, cisplatin was administered to various CRC cell lines to assess the role of the PI3K/FOXO pathway in such drug action and resistance [109]. Cisplatin caused apoptosis in sensitive cells and modified long-term cell survival, which was linked to FOXO3A nuclear translocation. FOXO3A dephosphorylation became impaired in resistant cells, thereby affecting target gene promoter transactivation (i.e. p27Kip1 and BIM). Cisplatin use, combined with $\mathrm{p} 38 \alpha$ pharmacological inhibition, has also been shown to be related to decreased cancer cell viability through increasing BAX-dependent apoptotic cell death by activating FOXO3A tumour suppressor properties [92]. Such activation was related to p21, PTEN, BIM and $G A D D$ upregulation, inducing apoptosis in CRC cells.

In another study, Luo et al., demonstrated that treating HCT116 and SW480 CRC cells with selenite inhibited $\mathrm{AKT}$ and the consequent accumulation of FOXO3A, thereby facilitating the transcription of target genes such as BIM and PTEN [88]. FOXO3A-mediated upregulation of PTEN contributed to enhancing the inhibitory effect on the AKT pathway. Selenite therefore seemed to induce ROS-dependent FOXO3A-mediated apoptosis in CRC cells. Regarding inflammation, treating HCT-8 and
HCT116 cells with docosahexaenoic acid (DHA, an omega-3 polyunsaturated fatty acid) produced the nuclear accumulation of FOXO3A, which bound to the miR-21 promoter, activating its repression [101]. The study by Fluckiger et al., demonstrated that RIP1 and AMPK $\alpha$ regulated FOXO3A-miR-21 signalling, modulating TNF $\alpha$ production after DHA treatment of CRC cells; this approach led to tumour growth inhibition and apoptosis. Administering genistein, a prominent component of soy, inhibited EFG-induced proliferation in HT-29 cells, favouring FOXO3A nuclear retention [86]. Other studies have described similar results when using other treatments such as cetuximab (a monoclonal antibody against EGFR) and quinazoline $[95,103]$.

Regarding studies describing reduced FOXO nuclear bioavailability, experimental approaches have included genetic engineering of cells and animal models, drug treatment and gene expression knock-down. It has been shown that proliferation of colonic epithelia and CRC cells via EGFR stimulation has been associated with a loss of FOXO3A activity (phosphorylation, translocation to the cytosol and degradation) and a decrease in its transactivation properties regarding the $p 27 \mathrm{kip}$ promoter [87]. Dehner et al., studied the transcriptional effect of WNT signalling pathway over-activation on HCT-116 cells [110]; they found that the $S G K 1$ gene was the most up regulated gene, thereafter leading to FOXO3A nuclear exclusion. This change in protein bioavailability in the nuclear compartment was associated with the inhibition of target gene expression and FOXO3A-induced apoptosis.

Another interesting study described the stimulation of intracytoplasmic lipid droplet (a dynamic organelle present in tumour tissues) density in human colon cancer cells which led to the loss of FOXO3A (via PI3KB) and a decrease in Sirtuin6 (SIRT6) lipid metabolism [89]. Furthermore, dissociation of FOXO3A from the p27kip1 promoter (and its subsequent decreased expression) stimulated CRC cell proliferation; a negative regulatory loop between LDs and FOXO3/SIRT6 was identified thereafter [99].

It has been shown that the DEAD box protein P68 (p68) and FOXO3A have differential expression in CRC (up- and down-regulation, respectively) [97]. Indeed, p68 has been seen to be related to a reduction in FOXO3A, via $A K T$, which contributed to $C R C$ oncogenesis in vitro and in vivo. Similarly, high REP1 (Rab escort protein) expression has been linked to a direct blockade (REP1 and FOXO3A are direct protein partners) of FOXO3A nuclear trans-localisation in CRC cells, which has suppressed FOXO3-mediated apoptosis [104]. In that study, REP1 inhibition, combined with 5-FU treatment, led to retarding tumour growth in mice, leading to it being proposed as a potential therapeutic target for CRC. FOXO3A inactivation has been related to reactive 
oxygen species (ROS) production during protein kinase CK2 downregulation-mediated senescence in human CRC cells [102]. This effect was facilitated by AKT-mediated phosphorylation of FOXO3A and the decreased transcription of several target genes, such as $\mathrm{Cu} /$ ZnSOD, MnSOD and catalase (CAT). Using Nlrc $3^{-/-}$mice has enabled showing that Nlrc3 regulates cell proliferation in CRC by reducing FOXO3A and FOXO1 activation $[105,119]$. These findings argue in favour of the therapeutic potential of regulating NLRC3 for treating CRC.

More recently it has been shown that Rho GTPase-activating protein 15 (RHGAP15) and FOXO1 expression was lower in CRC specimens than in normal colonic mucosa [106]. An increase in PTEN and FOXO1 was observed in ARHGAP15-overexpressed HT29 and RKO cells, along with decreased AKT phosphorylation. It was concluded that PTEN/AKT/FOXO1 signalling was participating in ARHGAP15 anti-proliferation and anti-invasion effects.

A series of studies has shown that FOXO transcript expression knock-down has enabled understanding potential regulatory mechanisms involved in CRC pathogenesis; indeed, different microRNAs (miRNA) have been studied in vivo and in vitro to assess FOXO tumour suppressor properties. It has been shown that miR-544 binds FOXO1, while miR-153 and miR-592 bind FOXO3A [91, 100, 120]. miR-96 has been described as binding to both FOXO1 and FOXO3A [94]. In all these cases the molecules' effects have contributed to CRC biology.

Most histopathological reports aiming to associate FOXO expression/localisation with disease outcome in cancer patients have described a role for FOXOs as tumour suppressors. Studying primary CRC tissues and their corresponding metastases has shown that FOXO3A levels became decreased during metastasis, thereby evoking a role for this protein as a cancer suppressor [45, 76]. However, its nuclear localisation has also been linked to lower overall CRC survival [115]. Taken together, these results pinpoint the complexity of FOXO regulatory networks and reinforce these transcription factors' dual role as cancer suppressors and oncogenes. In this context, using FOXOs expression levels for CRC diagnostic/prognostic purposes remains limited. Indeed, transcriptional data from CRC should be analysed globally considering dysregulation of key biological processes and molecular pathways. Interestingly, Tenbaum et al. have proposed the measurement of nuclear $\beta$-catenin as a biomarker of treatments leading to FOXO3A nuclear accumulation, which might predict apoptosis or metastasis [115]. In addition, this may be useful for molecules acting upstream, as AKT/ PI3K and tyrosine kinase inhibitors.
FOXM1: a major actor in cell cycle regulation

The FOXM1 gene (also known as MPP-2, WIN, $H F H-11$ and Trident), which is located at $12 \mathrm{p} 13-3$ in human species, has 10 alternatively spliced exons, leading to the synthesis of 3 protein isoforms (FOXM1a, b and c) $[43,121,122]$. It has been reported that the FOXM1 DBD was able to bind the canonical FKH motif (5'-RYAAAYA-3') on DNA for regulating target genes. Structurally, FOXM1 has several functional domains: the DBD, a strong acidic TAD located in the protein's C-terminal region, and a negative-regulatory domain in the N-terminal (NRD) [39] (and references therein) (Fig. 1). FOXM1 is well known for its function during cell cycle regulation and its localisation in the nuclear compartment depends on ERK phosphorylation on $\mathrm{Ser}^{331}$ and $\mathrm{Ser}^{704}$ residues [123]. It has been shown that the impaired activation of several receptor tyrosine kinases, such as RTK, RAF, RAS and MAPK2, in cancer cells has led to the nuclear accumulation of FOXM1, via ERK phosphorylation. FOXM1 is a master factor involved in G1/S and G2/M cell cycle transition and $M$ phase progression. It has been linked to normal chromosomal stability and segregation during mitosis [43]. FOXM1 has been associated with cellular senescence, stem cell-like self-renewal, cell differentiation and proliferation, tissue homeostasis, cell migration and invasion, DNA damage repair and angiogenesis, oxidative stress regulation, and drug resistance during tumorigenesis.

Regarding CRC biology, FOXM1 expression levels have been reported to be correlated with cancer progression, lymph node and liver metastasis and high TNM stages [124-127]. These findings agreed with decreased patient survival rate. Interestingly, high concurrent FOXM1 and CAV-1 (caveolin 1) overexpression plays an important role in CRC development and progression by negatively regulating E-cadherin [128].

The hedgehog $(\mathrm{Hh})$ signalling and the GLI proteins have been shown to be important actors in CRC development. Hh genes encode secreted proteins functioning as intercellular signalling molecules and participating in several developmental and adult tissue biological processes. GLI are zinc finger transcription factors, mainly having activating properties regarding target genes including $H h$, some of which (e.g. GLI1) have proto-oncogenic properties. Douard et al., found that overexpression of Sonic Hedgehog-SHh- (a member of the Hh family), GLI1 and FOXM1 was linked to increased cell proliferation in primary CRC tissue and cell lines [129]. It has recently been proven that GLI1 directly binds to and transactivates the FOXM1 promoter [130, 131] (Fig. 3). GANT61-treated HT-29 cells have displayed FOXM1 transcriptional impairment secondary to the inhibition of GLI binding to chromatin and RNA 

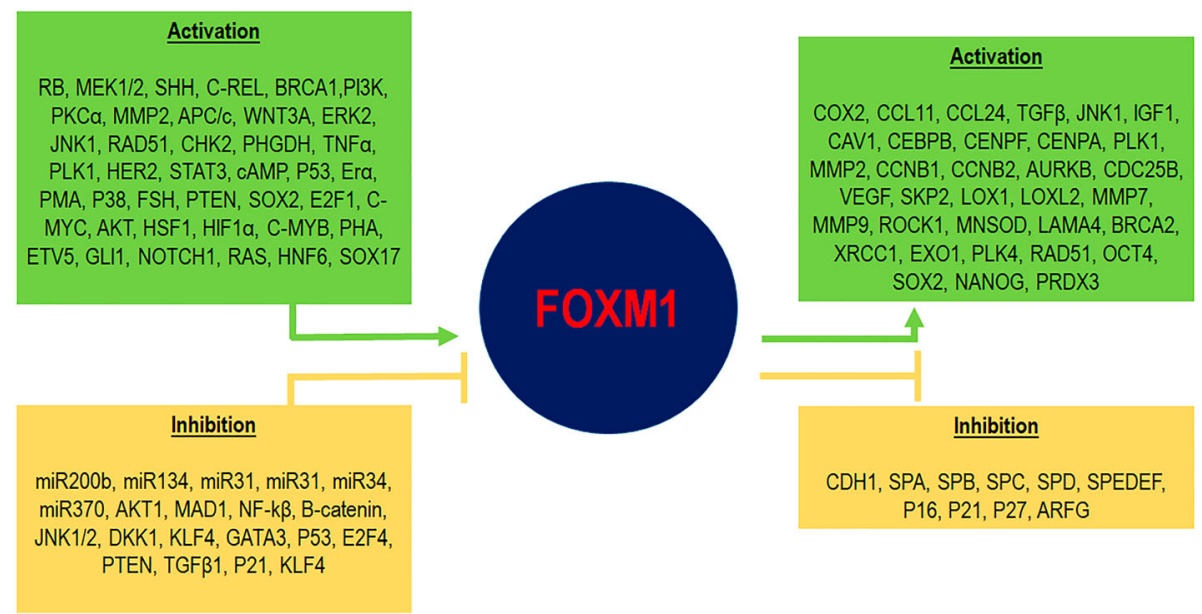

Fig. 3 FOXM1 upstream regulators and downstream effectors

polymerase to DNA [132]. Interestingly, GLI also participates in CRC metastasis by activating (via FOXM1) EMT and PI3K/AKT signalling pathways [131]. Regarding target gene downstream regulation, FOXM1 directly binds to PTTG1 and HSPA5 promoters participating in CRC cell invasion and migration [133, 134] (Fig. 3). Furthermore, FOXM1 directly binds to and transactivates the growth arrest-specific (GAS1) promoter of a gene involved in the negative regulation of oncogenesis and CRC metastasis $[135,136]$. The Fig. 3 includes a comprehensive list of regulators of FOXM1 and its effector genes.

Interestingly, FOXM1 has also been described as a relevant actor during mitochondrial metabolism. For instance, FOXM1 expression has activated peroxiredoxin-3 (Prx3) mitochondrial gene transcription and CD133 expression in colon cancer stem cells (CSC) [137, 138]. Increased PRX3 expression by FOXM1 has been seen to be related to mitochondrial activity maintenance via the elimination of ROS, thereby leading to colon CSC survival and stemness. A novel FOXM1 isoform has been identified more recently: FOXM1D [139]; FOXM1D has an essential function in Rho/ROCK activation, a signalling pathway involved in actin cytoskeleton organisation and cancer invasion. More precisely, FOXM1D overexpression contributes to actin assembly polymerisation and interferes with E-cadherin expression, which is related to metastasis.

Regarding miRNA mechanisms leading to FOXM1 knock-down, it has been shown that the downregulation of miR-320, miR-149, mi-R-342 is related to CRC biology [140-144]. Notably, miR-320 and miR-342 are suppressors of both FOXM1 and FOXQ1, constituting potentially interesting therapeutic tools for CRC [143, 144]. Clinically, FOXM1 may be used directly as a diagnostic/ prognostic marker as high expression levels have been correlated, in independent cohorts of CRC patients, with poor survival [144]. In addition, due to its clear oncogenic nature FOXM1 has emerged as promissory target for cancer drug therapy [145].

\section{FOXP3: a molecule at the crossroads of immunity and tumorigenesis}

The long story of the FOXP3 gene goes back 50 years to when the Oak Ridge National Laboratory's Mammalian Genetics Laboratory (USA) explored the genetic consequences of radiation on mammals [146]. This initiative led to the description of one of the most well-known strains of mouse having a spontaneous mutation carried by the X chromosome: the "scurfy" mouse $[147,148]$. It was stated that these animals' phenotype (characterised by scaly and ruffled skin, reddened eyes, abnormal spleen and lymph node growth and early death) originated from a Foxp3 2 bp out-of-frame insertion leading to a truncated protein product. Functionally, the phenotype was associated with an autoimmune phenomenon and a suppressor T-cell subset expressing Foxp3, CD4 and CD25 [149]. Thereafter, Foxp3 was described as a major molecular actor involved in regulatory T-cell (Treg) development and function [150-152]. The loss of Foxp3 in mice leads to a fatal lymphoproliferative disorder whilst its overexpression causes an immunodeficiency phenotype $[153,154]$. FOXP3 germline mutations in humans have been associated with the X-linked autoimmunity-allergic dysregulation syndrome, also known as immunodysregulation, polyendocrinopathy and enteropathy, X-linked (IPEX) syndrome [155-157].

FOXP3 is located in Xp11.23 in human beings and has 11 encoding exons which are translated into a 431-residue (47 kDa)-long protein [155]. Structurally, from the $\mathrm{N}$-ter to the $\mathrm{C}$-ter regions, FOXP3 consists of a proline-rich transcriptional repressor domain (TRD), a zinc finger, a leucine zipper motif (LZ) and the FOX-DBD containing the NLS [39, 158] (Fig. 1). Two 
principal FOXP3 isoforms are synthesised in human species, one issuing from the translation of the full length open reading frame and another lacking a specific region involved in retinoic acid-related orphan receptor $(\mathrm{ROR} \alpha)$ inhibition [159]. FOXP3 is mainly expressed by Treg cells, but it has also been found in other cells (e.g. B-lymphocytes) and various normal tissues (e.g. breast, prostate, lung, thymus, colon, kidney, ovary) [154, 160-162].

Interestingly, it has been found that Treg cells infiltrate various types of tumour-related tissue in mouse and human species, such as lung, liver, breast, ovary, pancreas, head, neck, gastrointestinal tract, skin and other tissues [163-165] (and references therein). The discovery of somatic mutations and epigenetic alterations has revealed a dual role for FOXP3 regarding cancer biology as it can act as an oncogene or a tumour suppressor gene (e.g. breast, cancer and prostate) [162, 166-169]. Numerous human cancer cell lines, including some having a colorectal origin (e.g. HCA 2.6, HCA 3.2), have different FOXP3 expression levels which has enabled assessing its function in different in vitro conditions [170]. Non-encoding sequence regulatory regions, minimal promoter trans-regulation and epigenetic mechanisms have been described regarding FOXP3's upstream regulation [148].

Due to the close relationship between Treg cells and tumours' microenvironment, FOXP3 has been widely studied in CRC development and progression. At least 80 studies on FOXP3 and CRC biology have been published to date; however, the usefulness of FoxP3 ${ }^{+}$-Tregs cells for clinical prognosis regarding CRC has been a subject for continuous debate. $\mathrm{Xu}$ et al., published a meta-analysis based on 18 previously-reported studies which examined $>3500$ patients, aiming to determine $\mathrm{FoxP}^{+}$prognostic role in CRC [171]. Numerous variables were considered for analysis in that study, such as specimen type (e.g. tissue, tissue microarray, blood), $\mathrm{FoxP3}^{+}$and other marker's testing methods (e.g. immunohistochemistry-IHC, quantitative real time polymerase chain reaction (qRT-PCR), flow cytometry analysis (FCM), CRC tumour stage, follow up time and survival. It was found that high $\mathrm{FoxP}^{+}$-Treg infiltration was linked to an improvement in cancer-specific survival. These findings were similar to those reported by Huang et al.'s meta-analysis (2014), but differed from those from other studies, probably due to differences in sample type and consistency during data analysis [171-177]. It has been shown that $\mathrm{FoxP}^{+}$non- $\mathrm{T}_{\text {reg }}$ cells can infiltrate some colorectal cancers (e.g. those having TGF- $\beta$ and IL-12 expression) leading to a better prognosis. It is worth noting that the difficulty of separating cell subpopulations may be a relevant factor contributing to contradictory findings in research involving immunohistochemistry [163, 178].
Regarding FOXP3's regulation, it has been shown that various proteins (e.g. NFAT, AP-1, FOXO1, FOXO3, CREB-ATF1, SAMD3, RAR-RXR, RUNX, ETS1, STAT5) are capable of directly binding to its promoter and other regulatory regions to activate its transcription [179-181]. The TGF $\beta$ molecule has been shown to be capable of inducing FoxP3 expression in $\mathrm{CD} 4{ }^{+} \mathrm{CD} 25^{+}$ cells [160].

Regarding downstream regulation, it has been proposed that FOXP3 may bind to more than 2800 TFBS in $\mathrm{T}_{\text {reg }}$ cells, representing $>700$ genes [182]; however, thousands of other genes are predicted to be indirectly regulated by FOXP3 via its interaction with numerous cofactors (e.g. NFAT, IRF4, RUNX1, EOS, IRF4, SATB1, LEF1, GATA1, TIP60 and p300) forming large protein complexes [181, 183, 184].

Thus, it can state that although the role of FOXP3 in CRC biogenesis is still not completely understood, numerous reports have argued in favour of a FoxP3+ Treg cell protective function by controlling carcinogenesis, improving local inflammation and, in fine, ameliorating patients' chances of survival.

\section{Other FOX proteins involved in CRC biology}

Several other FOX proteins have been described as important regulators of CRC tumorigenesis. However, since they have not been studied as extensively as those described above, they will not be widely reviewed in the present manuscript. For instance, FOXC1 and FOXC2 promote CRC metastasis by regulating ITGA7/FGFR4 and $M E T$ expression, respectively [185-187]. It has been stated that FOXQ1 plays a key regulatory role in epithelial-mesenchymal transition of several types of cancer, including CRC [188, 189]. FOXQ1 overexpression has been seen to play a relevant role in enhancing CRC tumorigenicity, tumour growth and migration/invasion of tumour cells by mainly acting on WNT and TGF-B molecular pathways [144, 190-192]. Other FOX proteins having oncogenic properties in CRC would include FOXA1, FOXD1, FOXD3, FOXF1, FOXF2 FOXJ1, FOXK1, FOXK2, FOXN3 and FOXR2 [46, 47, 65, 193-204]. Additional FOX TF studies have reported tumour suppressor properties for some of them, such as FOXE1, FOXF1, FOXF2 and FOXJ3 [205-210].

Although these factors deserve additional functional studies, some of them might be used in the future as diagnostic/prognostic studies for CRC.

\section{Targeting FOX molecules for CRC therapeutics and future research}

As stated above, TFs can have oncogenic or tumour suppressor properties, acting on various key molecular cascades involved in CRC pathogenesis. Classically, except for ligand-inducible nuclear receptors, TFs have been 
described as "undruggable" targets. However, several recent approaches aiming to regulate TF activity (enhancing or inhibiting it) have been proposed, several of which have been used in cancer biology studies [16, 211-214]. Regarding suppressor TFs, increasing their function has been obtained by using pharmacological approaches while other chemical strategies have been used to restore their function. TF oncogenic function has been inhibited by targeting their cofactors in different ways, such as using small-molecule and short-based peptide based approaches. On the whole, targeting TF methods includes those aiming to regulate their expression/degradation, perturb their protein/protein interactions and act on the TFBS-DBD. FOX factors have not been widely explored using these strategies, thereby underlining an interesting field for potential research regarding CRC therapy. Recently, FOX factors have been studied concerning various biological processes using different experimental designs based on using the CRISPR/Cas9 genome editing tool [215, 216]. Future therapy will combine CRISPR/Cas9 specific genome editing with classic drug treatment; using this approach for modulating $F O X$ gene function will certainly provide attractive therapy for CRC treatment.

\section{Conclusions}

FOX TFs are key molecular actors during CRC, which can act in distinct molecular cascades regulating several biological processes. Their target regulation by using classical therapeutic approaches and/or novel techniques might improve CRC prognosis. Future research and treatment should therefore involve their study at genomic, transcriptomic and proteomic levels. Certainly, blocking FOX TFs oncogenic properties during CRC development will contribute to improve patient outcomes.

\section{Abbreviations}

CIMP: CpG island methylator phenotype; CIN: Chromosomal instability; CRC: Colorectal cancer; DBD: DNA binding domain; FKH: Forkhead; FOX: The forkhead box; FOX-DBD: Forkhead domain; MSI: Microsatellite instability; NES: Nuclear export sequence; NLS: Nuclear localisation sequence; NRD: Negative-regulatory domain; TAD: Transactivation; TAD: Transactivation domain; TF: Transcription factors; TFBS: Transcription factor binding sites

\section{Acknowledgements}

Not applicable.

\section{Funding}

This study was supported by the Universidad del Rosario (grant: CS/ABN062/ GENIUROS 018).

\section{Availability of data and materials}

Data sharing is not applicable to this article as no datasets were generated or analysed during the current study.

\section{Author's contributions}

PL wrote the manuscript and created the figures. The author read and approved the final manuscript.
Ethics approval and consent to participate

Not applicable.

\section{Consent for publication}

Not applicable.

\section{Competing interests}

The authors declare that they have no competing interests.

\section{Publisher's Note}

Springer Nature remains neutral with regard to jurisdictional claims in published maps and institutional affiliations.

Received: 17 October 2018 Accepted: 1 January 2019

Published online: 08 January 2019

\section{References}

1. Torre LA, Bray F, Siegel RL, Ferlay J, Lortet-Tieulent J, Jemal A. Global cancer statistics, 2012. CA Cancer J Clin. 2015;65:87-108.

2. Favoriti P, Carbone G, Greco M, Pirozzi F, Pirozzi REM, Corcione F. Worldwide burden of colorectal cancer: a review. Updat Surg. 2016;68:7-11.

3. Ferlay J, Soerjomataram I, Dikshit R, Eser S, Mathers C, Rebelo M, et al. Cancer incidence and mortality worldwide: sources, methods and major patterns in GLOBOCAN 2012. Int J Cancer. 2015:136:E359-86.

4. Johnson CM, Wei C, Ensor JE, Smolenski DJ, Amos Cl, Levin B, et al. Metaanalyses of colorectal cancer risk factors. Cancer Causes Control. 2013;24: 1207-22

5. Strum WB. Colorectal Adenomas. N Engl J Med. 2016;375:389-90.

6. Gonzalez-Pons M, Cruz-Correa M. Colorectal cancer biomarkers: where are we now? Biomed Res Int. 2015;2015:1-14.

7. Simons CCJM, Hughes LAE, Smits KM, Khalid-de Bakker CA, de Bruïne AP, Carvalho B, et al. A novel classification of colorectal tumors based on microsatellite instability, the CpG island methylator phenotype and chromosomal instability: implications for prognosis. Ann Oncol. 2013;24: 2048-56.

8. Jasperson K, Burt RW. The genetics of colorectal cancer. Surg Oncol Clin N Am. 2015;24:683-703

9. Aran V, Victorino AP, Thuler LC, Ferreira CG. Colorectal cancer: epidemiology, disease mechanisms and interventions to reduce onset and mortality. Clin Colorectal Cancer. 2016:15:195-203.

10. Mahasneh A, Al-Shaheri F, Jamal E. Molecular biomarkers for an early diagnosis, effective treatment and prognosis of colorectal cancer: current updates. Exp Mol Pathol. 2017;102:475-83.

11. Guinney J, Dienstmann R, Wang X, de Reyniès A, Schlicker A, Soneson C, et al. The consensus molecular subtypes of colorectal cancer. Nat Med. 2015; 21:1350-6.

12. Roseweir AK, McMillan DC, Horgan PG, Edwards J. Colorectal cancer subtypes: translation to routine clinical pathology. Cancer Treat Rev. 2017; $57: 1-7$

13. Dienstmann R, Vermeulen L, Guinney J, Kopetz S, Tejpar S, Tabernero J. Consensus molecular subtypes and the evolution of precision medicine in colorectal cancer. Nat Rev Cancer. 2017;17:268.

14. Darnell JE. Transcription factors as targets for cancer therapy. Nat Rev Cancer. 2002;2:740-9.

15. Lee TI, Young RA. Transcriptional regulation and its misregulation in disease. Cell. 2013;152:1237-51

16. Bhagwat AS, Vakoc CR. Targeting transcription factors in cancer. Trends Cancer. 2015;1:53-65.

17. Bradner JE, Hnisz D, Young RA. Transcriptional addiction in cancer. Cell. 2017;168:629-43.

18. Jacob F, Monod J. Genetic regulatory mechanisms in the synthesis of proteins. J Mol Biol. 1961:3:318-56.

19. Todeschini A-L, Georges A, Veitia RA. Transcription factors: specific DNA binding and specific gene regulation. Trends Genet. 2014;30:211-9.

20. Deplancke B, Alpern D, Gardeux V. The genetics of transcription factor DNA binding variation. Cell. 2016;166:538-54

21. Boeva V. Analysis of genomic sequence motifs for deciphering transcription factor binding and transcriptional regulation in eukaryotic cells. Front Genet. 2016;7:24 
22. Rosanova A, Colliva A, Osella M, Caselle M. Modelling the evolution of transcription factor binding preferences in complex eukaryotes. Sci Rep. 2017;7:7596

23. Liu F, Wang L, Perna F, Nimer SD. Beyond transcription factors: how oncogenic signalling reshapes the epigenetic landscape. Nat Rev Cancer. 2016;16:359-72.

24. Ho L, Crabtree GR. Chromatin remodelling during development. Nature. 2010:463:474-84.

25. Bonasio R, Tu S, Reinberg D. Molecular signals of epigenetic states. Science. 2010;330:612-6.

26. Conaway RC, Conaway JW. Function and regulation of the Mediator complex. Curr Opin Genet Dev. 2011;21:225-30.

27. Bannister AJ, Kouzarides T. Regulation of chromatin by histone modifications. Cell Res. 2011;21:381-95.

28. Spitz F, Furlong EEM. Transcription factors: from enhancer binding to developmental control. Nat Rev Genet. 2012;13:613-26.

29. Yusuf D, Butland SL, Swanson MI, Bolotin E, Ticoll A, Cheung WA, et al. The transcription factor encyclopedia. Genome Biol. 2012;13:R24.

30. Altobelli G. Bioinformatics applied to gene transcription regulation. J Mol Endocrinol. 2012;49:R51-9.

31. Kilpinen H, Waszak SM, Gschwind AR, Raghav SK, Witwicki RM, Orioli A, et al. Coordinated effects of sequence variation on DNA binding, chromatin structure, and transcription. Science. 2013;342:744-7.

32. Sandmann T, Jensen $\sqcup$, Jakobsen JS, Karzynski MM, Eichenlaub MP, Bork P, et al. A temporal map of transcription factor activity: mef2 directly regulates target genes at all stages of muscle development. Dev Cell. 2006;10:797-807.

33. Siggers T, Duyzend MH, Reddy J, Khan S, Bulyk ML. Non-DNA-binding cofactors enhance DNA-binding specificity of a transcriptional regulatory complex. Mol Syst Biol. 2014;7:555.

34. Slattery M, Riley T, Liu P, Abe N, Gomez-Alcala P, Dror I, et al. Cofactor binding evokes latent differences in DNA binding specificity between Hox proteins. Cell. 2011;147:1270-82.

35. Cusanovich DA, Pavlovic B, Pritchard JK, Gilad Y. The functional consequences of variation in transcription factor binding. PLoS Genet. 2014 10:e1004226 Pilpel Y, editor.

36. Myatt SS, Lam EW-F-F. The emerging roles of forkhead box (Fox) proteins in cancer. Nat Rev Cancer. 2007;7:847-59.

37. Hannenhalli $\mathrm{S}$, Kaestner $\mathrm{KH}$. The evolution of Fox genes and their role in development and disease. Nat Rev Genet. 2009;10:233-40.

38. Benayoun BA, Caburet S, Veitia RA. Forkhead transcription factors: key players in health and disease. Trends Genet. 2011;27:224-32.

39. Lam EW-F, Brosens JJ, Gomes AR, Koo C-Y. Forkhead box proteins: tuning forks for transcriptional harmony. Nat Rev Cancer. 2013;13:482-95.

40. Katoh MM, Igarashi M, Fukuda H, Nakagama H, Katoh MM. Cancer genetics and genomics of human FOX family genes. Cancer Lett. 2013;328:198-206.

41. Lam EW-F, Gomes AR. Forkhead box transcription factors in cancer initiation, progression and chemotherapeutic drug response. Front Oncol. 2014;44:305.

42. Golson ML, Kaestner KH. Fox transcription factors: from development to disease. Development. 2016;143:4558-70.

43. Koo C-Y, Muir KW, Lam EW-F. FOXM1: from cancer initiation to progression and treatment. Biochim Biophys Acta. 1819;2012:28-37.

44. Halasi M, Gartel AL. FOX(M1) news-it is cancer. Mol Cancer Ther. 2013;12: 245-54.

45. Bullock MD, Bruce A, Sreekumar R, Curtis N, Cheung T, Reading I, et al. FOXO3 expression during colorectal cancer progression: biomarker potential reflects a tumour suppressor role. Br J Cancer. 2013;109:387-94.

46. Wang W, Li X, Lee $M$, Jun S, Aziz KE, Feng L, et al. FOXKs promote Wnt/ $\beta$ catenin signaling by translocating DVL into the nucleus. Dev Cell. 2015;32: 707-18.

47. Liu K, Fan J, Wu J. Forkhead box protein J1 (FOXJ1) is overexpressed in colorectal cancer and promotes nuclear translocation of $\beta$-catenin in SW620 cells. Med Sci Monit. 2017;23:856-66.

48. Bach D-H, Long NP, Luu T-T-T, Anh NH, Kwon SW, Lee SK. The dominant role of Forkhead box proteins in cancer. Int J Mol Sci. 2018;19.

49. Mukherjee A, Hollern DP, Williams OG, Rayburn TS, Byrd WA, Yates $C$, et al. A review of FOXI3 regulation of development and possible roles in cancer progression and metastasis. Front Cell Dev Biol. 2018;6:69.

50. Weigel $D$, Jürgens $G$, Küttner $F$, Seifert $E$, Jäckle $H$. The homeotic gene fork head encodes a nuclear protein and is expressed in the terminal regions of the Drosophila embryo. Cell. 1989;57:645-58.
51. Weigel $D$, Jäckle $H$. The fork head domain: a novel DNA binding motif of eukaryotic transcription factors? Cell. 1990;63:455-6.

52. Katoh M, Katoh M. Human FOX gene family (review). Int J Oncol. 2004;25: 1495-500.

53. Jackson BC, Carpenter C, Nebert DW, Vasiliou V. Update of human and mouse forkhead box (FOX) gene families. Hum Genomics. 2010:4:345-52.

54. Shimeld SM, Degnan B, Luke GN. Evolutionary genomics of the Fox genes: origin of gene families and the ancestry of gene clusters. Genomics. 2010; 95:256-60.

55. Lai E, Clark KL, Burley SK, Darnell JE. Hepatocyte nuclear factor $3 /$ fork head or "winged helix" proteins: a family of transcription factors of diverse biologic function. Proc Natl Acad Sci U S A. 1993;90:10421-3.

56. Overdier DG, Porcella A, Costa RH. The DNA-binding specificity of the hepatocyte nuclear factor 3/forkhead domain is influenced by amino-acid residues adjacent to the recognition helix. Mol Cell Biol. 1994;14:2755-66.

57. Nakagawa S, Gisselbrecht SS, Rogers JM, Hartl DL, Bulyk ML. DNA-binding specificity changes in the evolution of forkhead transcription factors. Proc Natl Acad Sci. 2013;110:12349-54.

58. Marsden I, Jin C, Liao X. Structural changes in the region directly adjacent to the DNA-binding helix highlight a possible mechanism to explain the observed changes in the sequence-specific binding of winged helix proteins. J Mol Biol. 1998;278:293-9.

59. Clark KL, Halay ED, Lai E, Burley SK. Co-crystal structure of the HNF-3/fork head DNA-recognition motif resembles histone H5. Nature. 1993;364:412-20.

60. Obsil T, Obsilova V. Structure/function relationships underlying regulation of FOXO transcription factors. Oncogene. 2008;27:2263-75.

61. Cirillo LA, Zaret KS. Specific interactions of the wing domains of FOXA1 transcription factor with DNA. J Mol Biol. 2007;366:720-4.

62. Caburet S, Demarez A, Moumné L, Fellous M, De Baere E, Veitia RA. A recurrent polyalanine expansion in the transcription factor FOXL2 induces extensive nuclear and cytoplasmic protein aggregation. J Med Genet. 2004;41:932-6.

63. Moumne L, Dipietromaria A, Batista F, Kocer A, Fellous M, Pailhoux E, et al. Differential aggregation and functional impairment induced by polyalanine expansions in FOXL2, a transcription factor involved in cranio-facial and ovarian development. Hum Mol Genet. 2007;17:1010-9.

64. Zhao $Y, M a H$, Wang $Y, G a o ~ H, X i C$, Hua T, et al. Association between FOXP2 gene and speech sound disorder in Chinese population. Psychiatry Clin Neurosci. 2010;64:565-73.

65. Berman $\mathrm{H}$, Henrick K, Nakamura $\mathrm{H}$. Announcing the worldwide protein data bank. Nat Struct Mol Biol. 2003;10:980.

66. Wang Y, Zhou Y, Graves DT. FOXO transcription factors: their clinical significance and regulation. Biomed Res Int. 2014;2014:1-13.

67. Brent MM, Anand R, Marmorstein R. Structural basis for DNA recognition by FoxO1 and its regulation by posttranslational modification. Structure. 2008; 16:1407-16.

68. Hou T, Li Z, Zhao Y, Zhu W-G. Mechanisms controlling the anti-neoplastic functions of FoxO proteins. Semin Cancer Biol. 2018:50:101-14.

69. Eijkelenboom A, Burgering BMT. FOXOs: signalling integrators for homeostasis maintenance. Nat Rev Mol Cell Biol. 2013;14:83-97.

70. Martins R, Lithgow GJ, Link W. Long live FOXO: unraveling the role of FOXO proteins in aging and longevity. Aging Cell. 2016;15:196-207.

71. Liu Y, Ao X, Ding W, Ponnusamy M, Wu W, Hao X, et al. Critical role of FOXO3a in carcinogenesis. Mol Cancer. 2018;17:104.

72. Lu C, Yang Z, Jiang S, Yang Y, Han Y, Lv J, et al. Forkhead box $\mathrm{O} 4$ transcription factor in human neoplasms: cannot afford to lose the novel suppressor. J Cell Physiol. 2018. (Epub ahead of print). https://doi.org/10.1002/jcp.27853.

73. Luo CT, Li MO. Foxo transcription factors in T cell biology and tumor immunity. Semin Cancer Biol. 2018;50:13-20

74. González-Quiroz M, Urra H, Limia CM, Hetz C. Homeostatic interplay between FoxO proteins and ER proteostasis in cancer and other diseases. Semin Cancer Biol. 2018;50:42-52.

75. Yadav RK, Chauhan AS, Zhuang L, Gan B. FoxO transcription factors in cancer metabolism. Semin Cancer Biol. 2018;50:65-76.

76. Hornsveld M, Dansen TB, Derksen PW, Burgering BMT. Re-evaluating the role of FOXOs in cancer. Semin Cancer Biol. 2018;50:90-100.

77. Brunet A, Park J, Tran H, Hu LS, Hemmings BA, Greenberg ME. Protein kinase SGK mediates survival signals by phosphorylating the forkhead transcription factor FKHRL1 (FOXO3a). Mol Cell Biol. 2001:21:952-65.

78. van der Heide LP, Hoekman MFM, Smidt MP. The ins and outs of FoxO shuttling: mechanisms of FoxO translocation and transcriptional regulation. Biochem J. 2004;380:297-309. 
79. Calnan DR, Brunet A. The FoxO code. Oncogene. 2008;27:2276-88.

80. Coomans de Brachène $A$, Demoulin J-B. FOXO transcription factors in cancer development and therapy. Cell Mol Life Sci. 2016;73:1159-72.

81. Brunet A, Bonni A, Zigmond MJ, Lin MZ, Juo P, Hu LS, et al. Akt promotes cell survival by phosphorylating and inhibiting a Forkhead transcription factor. Cell. 1999;96:857-68.

82. Hu MC-T, Lee D-F, Xia W, Golfman LS, Ou-Yang F, Yang J-Y, et al. IkappaB kinase promotes tumorigenesis through inhibition of forkhead FOXO3a. Cell. 2004;117:225-37.

83. Yang J-Y, Zong CS, Xia W, Yamaguchi H, Ding Q, Xie X, et al. ERK promotes tumorigenesis by inhibiting FOXO3a via MDM2-mediated degradation. Nat Cell Biol. 2008;10:138-48.

84. Fu Z, Tindall DJ. FOXOs, cancer and regulation of apoptosis. Oncogene. 2008;27:2312-9.

85. Ho KK, Myatt SS, Lam EW-F. Many forks in the path: cycling with FoxO. Oncogene. 2008;27:2300-11.

86. Qi W, Weber CR, Wasland K, Savkovic SD. Genistein inhibits proliferation of colon cancer cells by attenuating a negative effect of epidermal growth factor on tumor suppressor FOXO3 activity. BMC Cancer. 2011;11:219.

87. Qi W, Weber CR, Wasland K, Roy H, Wali R, Joshi S, et al. Tumor suppressor FOXO3 mediates signals from the EGF receptor to regulate proliferation of colonic cells. Am J Physiol Liver Physiol. 2011;300:G264-72.

88. Luo H, Yang Y, Duan J, Wu P, Jiang Q, Xu C. PTEN-regulated AKT/FoxO3a/ Bim signaling contributes to reactive oxygen species-mediated apoptosis in selenite-treated colorectal cancer cells. Cell Death Dis. 2013;4:e481.

89. Qi W, Fitchev PS, Cornwell ML, Greenberg J, Cabe M, Weber CR, et al. FOXO3 growth inhibition of colonic cells is dependent on intraepithelial lipid droplet density. J Biol Chem. 2013;288:16274-81.

90. Shoeb M, Ramana KV, Srivastava SK. Aldose reductase inhibition enhances TRAlLinduced human colon cancer cell apoptosis through AKT/FOXO3a-dependent upregulation of death receptors. Free Radic Biol Med. 2013;63:280-90.

91. Zhang L, Pickard K, Jenei V, Bullock MD, Bruce A, Mitter R, et al. miR-153 supports colorectal cancer progression via pleiotropic effects that enhance invasion and chemotherapeutic resistance. Cancer Res. 2013;73:6435-47.

92. Germani A, Matrone A, Grossi V, Peserico A, Sanese P, Liuzzi M, et al. Targeted therapy against chemoresistant colorectal cancers: inhibition of p38a modulates the effect of cisplatin in vitro and in vivo through the tumor suppressor FoxO3A. Cancer Lett. 2014;344:110-8.

93. Cui Y-M, Jiang D, Zhang S-H, Wu P, Ye Y-P, Chen C-M, et al. FOXC2 promotes colorectal cancer proliferation through inhibition of $\mathrm{FOXO3a}$ and activation of MAPK and AKT signaling pathways. Cancer Lett. 2014;353:87-94.

94. Gao F, Wang W. MicroRNA-96 promotes the proliferation of colorectal cancer cells and targets tumor protein p53 inducible nuclear protein 1, forkhead box protein 01 (FOXO1) and FOXO3a. Mol Med Rep. 2015;11:1200-6.

95. Qazi AK, Hussain A, Khan S, Aga MA, Behl A, Ali S, et al. Quinazoline based small molecule exerts potent tumour suppressive properties by inhibiting PI3K/Akt/FoxO3a signalling in experimental colon cancer. Cancer Lett. 2015; 359:47-56.

96. Prabhu W, Allen JE, Dicker DT, El-Deiry WS. Small-molecule ONC201/TIC10 targets chemotherapy-resistant colorectal cancer stem-like cells in an Akt/ Foxo3a/TRAlL-dependent manner. Cancer Res. 2015:75:1423-32.

97. Sarkar M, Khare V, Guturi KKN, Das N, Ghosh MK. The DEAD box protein p68: a crucial regulator of AKT/FOXO3a signaling axis in oncogenesis. Oncogene. 2015;34:5843-56.

98. Kops GJPL, Medema RH, Glassford J, Essers MAG, Dijkers PF, Coffer PJ, et al. Control of cell cycle exit and entry by protein kinase B-regulated forkhead transcription factors. Mol Cell Biol. 2002;22:2025-36.

99. Penrose H, Heller S, Cable C, Makboul R, Chadalawada G, Chen Y, et al. Epidermal growth factor receptor mediated proliferation depends on increased lipid droplet density regulated via a negative regulatory loop with FOXO3/Sirtuin6. Biochem Biophys Res Commun. 2016:469:370-6.

100. Fu Q, Du Y, Yang C, Zhang D, Zhang N, Liu X, et al. An oncogenic role of miR-592 in tumorigenesis of human colorectal cancer by targeting Forkhead Box O3A (FoxO3A). Expert Opin Ther Targets. 2016;20:771-82.

101. Fluckiger $A$, Dumont $A$, Derangère $V$, Rébé $C$, de Rosny $C$, Causse $S$, et al. Inhibition of colon cancer growth by docosahexaenoic acid involves autocrine production of TNFa. Oncogene. 2016;35:4611-22.

102. Park S-Y, Bae Y-S. Inactivation of the FoxO3a transcription factor is associated with the production of reactive oxygen species during protein kinase CK2 downregulation-mediated senescence in human colon cancer and breast cancer cells. Biochem Biophys Res Commun. 2016;478:18-24.
103. Marzi L, Combes E, Vié N, Ayrolles-Torro A, Tosi D, Desigaud D, et al. FOXO3a and the MAPK p38 are activated by cetuximab to induce cell death and inhibit cell proliferation and their expression predicts cetuximab efficacy in colorectal cancer. Br J Cancer. 2016;115:1223-33.

104. Song K-H, Woo SR, Chung J-Y, Lee H-J, Oh SJ, Hong S-O, et al. REP1 inhibits FOXO3-mediated apoptosis to promote cancer cell survival. Cell Death Dis. 2017;8:e2536

105. Karki R, Malireddi RKS, Zhu Q, Kanneganti T-D. NLRC3 regulates cellular proliferation and apoptosis to attenuate the development of colorectal cancer. Cell Cycle. 2017;16:1243-51.

106. Pan S, Deng Y, Fu J, Zhang Y, Zhang Z, Ru X, et al. Decreased expression of ARHGAP15 promotes the development of colorectal cancer through PTEN/ AKT/FOXO1 axis. Cell Death Dis. 2018:9:673.

107. Yang Z, Liu S, Zhu M, Zhang H, Wang J, Xu Q, et al. PS341 inhibits hepatocellular and colorectal cancer cells through the FOXO3/CTNNB1 signaling pathway. Sci Rep. 2016;6:22090.

108. Xie J, Xiang D-B, Wang H, Zhao C, Chen J, Xiong F, et al. Inhibition of Tcf-4 induces apoptosis and enhances chemosensitivity of colon cancer cells. PLoS One. 2012;7:e45617.

109. Fernández de Mattos S, Villalonga P, Clardy J, Lam EW-F. FOXO3a mediates the cytotoxic effects of cisplatin in colon cancer cells. Mol Cancer Ther. 2008;7:3237-46.

110. Dehner M, Hadjihannas M, Weiske J, Huber O, Behrens J. Wnt signaling inhibits Forkhead box O3a-induced transcription and apoptosis through upregulation of serum- and glucocorticoid-inducible kinase 1. J Biol Chem. 2008:283:19201-10

111. Ericson K, Gan C, Cheong I, Rago C, Samuels Y, Velculescu VE, et al. Genetic inactivation of AKT1, AKT2, and PDPK1 in human colorectal cancer cells clarifies their roles in tumor growth regulation. Proc Natl Acad Sci. 2010;107: 2598-603.

112. Sun Y, Zhao S, Tian H, Xie X, Xiao F, Li K, et al. Depletion of PI3K p85alpha induces cell cycle arrest and apoptosis in colorectal cancer cells. Oncol Rep. 2009;22:1435-41.

113. Nasir O, Wang K, Föller M, Gu S, Bhandaru M, Ackermann TF, et al. Relative resistance of SGK1 knockout mice against chemical carcinogenesis. IUBMB Life. 2009:61:768-76.

114. Wu L, Li H, Jia CY, Cheng W, Yu M, Peng M, et al. MicroRNA-223 regulates FOXO1 expression and cell proliferation. FEBS Lett. 2012;586:1038-43.

115. Tenbaum SP, Ordóñez-Morán P, Puig I, Chicote I, Arqués O, Landolfi S, et al. $\beta$-catenin confers resistance to PI3K and AKT inhibitors and subverts FOXO3a to promote metastasis in colon cancer. Nat Med. 2012;18:892-901.

116. Khan KH, Yap TA, Yan L, Cunningham D. Targeting the PI3K-AKT-mTOR signaling network in cancer. Chin J Cancer. 2013;32:253-65.

117. Vanhaesebroeck B, Guillermet-Guibert J, Graupera M, Bilanges B. The emerging mechanisms of isoform-specific PI3K signalling. Nat Rev Mol Cell Biol. 2010;11:329-41.

118. Tzivion G, Dobson M, Ramakrishnan G. FoxO transcription factors; regulation by AKT and 14-3-3 proteins. Biochim Biophys Acta. 1813;2011:1938-45.

119. Karki R, Man SM, Malireddi RKS, Kesavardhana S, Zhu Q, Burton AR, et al. NLRC3 is an inhibitory sensor of PI3K-mTOR pathways in cancer. Nature. 2016:540:583-7.

120. Yao G, Zhang Y, Chen P, Ren X. MicroRNA-544 promotes colorectal cancer progression by targeting forkhead box 01. Oncol Lett. 2017;15:991-7.

121. Korver W, Roose J, Heinen K, Weghuis DO, de Bruijn D, van Kessel AG, et al. The HumanTRIDENT/HFH-11/FKHL16Gene: structure, localization, and promoter characterization. Genomics. 1997;46:435-42.

122. Yao KM, Sha M, Lu Z, Wong GG. Molecular analysis of a novel winged helix protein, WIN. Expression pattern, DNA binding property, and alternative splicing within the DNA binding domain. J Biol Chem. 1997; 272:19827-36

123. Ma RYM. Raf/MEK/MAPK signaling stimulates the nuclear translocation and transactivating activity of FOXM1c. J Cell Sci. 2005;118:795-806.

124. Chu X-Y, Zhu Z-M, Chen L-B, Wang J-H, Su Q-S, Yang J-R, et al. FOXM1 expression correlates with tumor invasion and a poor prognosis of colorectal cancer. Acta Histochem. 2012;114:755-62.

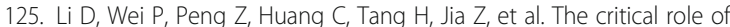
dysregulated FOXM1-PLAUR signaling in human colon cancer progression and metastasis. Clin Cancer Res. 2013;19:62-72.

126. Zhang HG, Xu XW, Shi XP, Han BW, Li ZH, Ren WH, et al. Overexpression of forkhead box protein M1 (FOXM1) plays a critical role in colorectal cancer. Clin Transl Oncol. 2016;18:527-32. 
127. Zhang $H$, Zhong $H$, Li L, Ji W, Zhang X. Overexpressed transcription factor FOXM1 contributes to the progression of colorectal cancer. Mol Med Rep. 2016;13:2696-700

128. Zhang J, Zhang K, Zhou L, Wu W, Jiang T, Cao J, et al. Expression and potential correlation among Forkhead box protein M1, Caveolin-1 and Ecadherin in colorectal cancer. Oncol Lett. 2016;12:2381-8.

129. Douard R, Moutereau S, Pernet $P$, Chimingqi M, Allory $Y$, Manivet $P$, et al. Sonic Hedgehog-dependent proliferation in a series of patients with colorectal cancer. Surgery. 2006;139:665-70

130. Wang D, Hu G, Du Y, Zhang C, Lu Q, Lv N, et al. Aberrant activation of hedgehog signaling promotes cell proliferation via the transcriptional activation of forkhead Box M1 in colorectal cancer cells. J Exp Clin Cancer Res. 2017:36:23.

131. Zhang C, Wang Y, Feng Y, Zhang Y, Ji B, Wang S, et al. Gli1 promotes colorectal cancer metastasis in a Foxm1-dependent manner by activating EMT and PI3K-AKT signaling. Oncotarget. 2016;7:86134-47.

132. Zhang R, Wu J, Ferrandon S, Glowacki KJ, Houghton JA. Targeting GLI by GANT61 involves mechanisms dependent on inhibition of both transcription and DNA licensing. Oncotarget. 2016;7:80190-207.

133. Zheng Y, Guo J, Zhou J, Lu J, Chen Q, Zhang C, et al. FoxM1 transactivates PTTG1 and promotes colorectal cancer cell migration and invasion. BMC Med Genet. 2015;8:49.

134. Luo X, Yao J, Nie $P$, Yang Z, Feng H, Chen $P$, et al. FOXM1 promotes invasion and migration of colorectal cancer cells partially dependent on HSPA5 transactivation. Oncotarget. 2016;7:26480-95.

135. Jiang Z, Xu Y, Cai S. Down-regulated GAS1 expression correlates with recurrence in stage II and III colorectal cancer. Hum Pathol. 2011;42:361-8.

136. Li Q, Qin Y, Wei P, Lian P, Li Y, Xu Y, et al. Gas1 inhibits metastatic and metabolic phenotypes in colorectal carcinoma. Mol Cancer Res. 2016;14: $830-40$

137. Song I-S, Jeong YJ, Jeong SH, Heo HJ, Kim HK, Bae KB, et al. FOXM1-induced PRX3 regulates stemness and survival of colon cancer cells via maintenance of mitochondrial function. Gastroenterology. 2015;149:1006-1016.e9.

138. Song I-S, Jeong YJ, Han J. Mitochondrial metabolism in cancer stem cells: a therapeutic target for colon cancer. BMB Rep. 2015;48:539-40.

139. Zhang $X$, Zhang $L$, Du $Y$, Zheng $H$, Zhang $P$, Sun $Y$, et al. A novel FOXM1 isoform, FOXM1D, promotes epithelial-mesenchymal transition and metastasis through ROCKs activation in colorectal cancer. Oncogene. 2017; 36:807-19

140. Wan L-Y, Deng J, Xiang X-J, Zhang L, Yu F, Chen J, et al. miR-320 enhances the sensitivity of human colon cancer cells to chemoradiotherapy in vitro by targeting FOXM1. Biochem Biophys Res Commun. 2015;457:125-32.

141. Xu K, Liu X, Mao X, Xue L, Wang R, Chen L, et al. MicroRNA-149 suppresses colorectal Cancer cell migration and invasion by directly targeting forkhead box transcription factor FOXM1. Cell Physiol Biochem. 2015;35:499-515.

142. Liu X, Xie T, Mao X, Xue L, Chu X, Chen L. MicroRNA-149 increases the sensitivity of colorectal cancer cells to 5 -fluorouracil by targeting forkhead box transcription factor FOXM1. Cell Physiol Biochem. 2016;39:617-29.

143. Vishnubalaji R, Hamam R, Yue S, Al-Obeed O, Kassem M, Liu F-F, et al. MicroRNA-320 suppresses colorectal cancer by targeting SOX4, FOXM1, and FOXQ1. Oncotarget. 2016;7:35789-802.

144. Weng W, Okugawa Y, Toden S, Toiyama Y, Kusunoki M, Goel A. FOXM1 and FOXQ1 are promising prognostic biomarkers and novel targets of tumorsuppressive miR-342 in human colorectal cancer. Clin Cancer Res. 2016;22: 4947-57.

145. Xu X-S, Miao R-C, Wan Y, Zhang L-Q, Qu K, Liu C. FoxM1 as a novel therapeutic target for cancer drug therapy. Asian Pac J Cancer Prev. 2015;16: 23-9.

146. Russell WL. X-ray-induced mutations in mice. Cold Spring Harb Symp Quant Biol. 1951;16:327-36.

147. Russell WL, Russell LB, Gower JS. Exceptional inheritance of a sex-linked gene in the mouse explained on the basis that the X/O sex-chromosome constitution is female. Proc Natl Acad Sci U S A. 1959;45:554-60.

148. Ramsdell F, Ziegler SF. FOXP3 and scurfy: how it all began. Nat Rev Immunol. 2014;14:343-9.

149. Shevach EM. Regulatory T cells in autoimmmunity*. Annu Rev Immunol. 2000;18:423-49.

150. Fontenot JD, Gavin MA, Rudensky AY. Foxp3 programs the development and function of CD4+CD25+ regulatory T cells. Nat Immunol. 2003;4:330-6.

151. Khattri R, Cox T, Yasayko S-A, Ramsdell F. An essential role for Scurfin in CD4 +CD25+ T regulatory cells. Nat Immunol. 2003;4:337-42.
152. Campbell DJ, Ziegler SF. FOXP3 modifies the phenotypic and functional properties of regulatory T cells. Nat Rev Immunol. 2007;7:305-10.

153. Brunkow ME, Jeffery EW, Hjerrild KA, Paeper B, Clark LB, Yasayko SA, et al. Disruption of a new forkhead/winged-helix protein, scurfin, results in the fatal lymphoproliferative disorder of the scurfy mouse. Nat Genet. 2001;27:68-73.

154. Triulzi T, Tagliabue E, Balsari A, Casalini P. FOXP3 expression in tumor cells and implications for cancer progression. J Cell Physiol. 2013;228:30-5.

155. Chatila TA, Blaeser F, Ho N, Lederman HM, Voulgaropoulos C, Helms C, et al. $J M 2$, encoding a fork head-related protein, is mutated in X-linked autoimmunity-allergic disregulation syndrome. J Clin Invest. 2000;106:R75-81.

156. Bacchetta R, Barzaghi F, Roncarolo M-G. From IPEX syndrome to FOXP3 mutation: a lesson on immune dysregulation. Ann N Y Acad Sci. 2018; 1417:5-22.

157. Wildin RS, Ramsdell F, Peake J, Faravelli F, Casanova JL, Buist N, et al. X-linked neonatal diabetes mellitus, enteropathy and endocrinopathy syndrome is the human equivalent of mouse scurfy. Nat Genet. 2001:27:18-20.

158. Lopes JE, Torgerson TR, Schubert LA, Anover SD, Ocheltree EL, Ochs HD, et al. Analysis of FOXP3 reveals multiple domains required for its function as a transcriptional repressor. J Immunol. 2006;177:3133-42.

159. Allan SE. The role of 2 FOXP3 isoforms in the generation of human CD4+ Tregs. J Clin Invest. 2005;115:3276-84.

160. Mercer F, Unutmaz D. The biology of FoxP3: a key player in immune suppression during infections, autoimmune diseases and cancer. Adv Exp Med Biol. 2009;665:47-59.

161. Martin F, Ladoire S, Mignot G, Apetoh L, Ghiringhelli F. Human FOXP3 and cancer. Oncogene. 2010;29:4121-9.

162. Szylberg $Ł$, Karbownik D, Marszałek A. The role of FOXP3 in human cancers. Anticancer Res. 2016:36:3789-94.

163. Takeuchi $Y$, Nishikawa $H$. Roles of regulatory T cells in cancer immunity. Int Immunol. 2016;28:401-9.

164. Tanaka A, Sakaguchi S. Regulatory T cells in cancer immunotherapy. Cell Res. 2017;27:109-18.

165. Ward-Hartstonge KA, Kemp RA. Regulatory T-cell heterogeneity and the cancer immune response. Clin Transl Immunol. 2017;6:e154.

166. Zuo T, Wang L, Morrison C, Chang X, Zhang H, Li W, et al. FOXP3 is an Xlinked breast cancer suppressor gene and an important repressor of the HER-2/ErbB2 oncogene. Cell. 2007:129:1275-86.

167. Katoh H, Zheng P, Liu Y. Signalling through FOXP3 as an X-linked tumor suppressor. Int J Biochem Cell Biol. 2010;42:1784-7.

168. Wang L, Liu R, Ribick M, Zheng P, Liu Y. FOXP3 as an X-linked tumor suppressor. Discov Med. 2010;10:322-8.

169. Redpath M, Xu B, van Kempen LC, Spatz A. The dual role of the X-linked FoxP3 gene in human cancers. Mol Oncol. 2011;5:156-63.

170. Karanikas V, Speletas M, Zamanakou M, Kalala F, Loules G, Kerenidi T, et al. Foxp3 expression in human cancer cells. J Transl Med. 2008;6:19.

171. Xu P, Fan W, Zhang Z, Wang J, Wang P, Li Y, et al. The clinicopathological and prognostic implications of FoxP3+ regulatory $T$ cells in patients with colorectal cancer: a meta-analysis. Front Physiol. 2017;8:950

172. Sinicrope FA, Rego RL, Ansell SM, Knutson KL, Foster NR, Sargent DJ. Intraepithelial effector (CD3+)/regulatory (FoxP3+) T-cell ratio predicts a clinical outcome of human colon carcinoma. Gastroenterology. 2009;137: 1270-9.

173. Fridman WH, Pagès $F$, Sautès-Fridman C, Galon J. The immune contexture in human tumours: impact on clinical outcome. Nat Rev Cancer. 2012:12: 298-306.

174. Suzuki H, Onishi H, Morisaki T, Tanaka M, Katano M. Intratumoral FOXP3 +VEGFR2+ regulatory $T$ cells are predictive markers for recurrence and survival in patients with colorectal cancer. Clin Immunol. 2013;146:26-33.

175. Huang Y, Liao H, Zhang Y, Yuan R, Wang F, Gao Y, et al. Prognostic value of tumor-infiltrating FoxP3+ T cells in gastrointestinal cancers: a meta analysis. PLoS One. 2014:9:e94376 Seno M, editor.

176. Shang B, Liu Y, Jiang S, Liu Y. Prognostic value of tumor-infiltrating FoxP3+ regulatory $T$ cells in cancers: a systematic review and meta-analysis. Sci Rep. 2015;5:15179.

177. Yoon HH, Orrock JM, Foster NR, Sargent DJ, Smyrk TC, Sinicrope FA Prognostic impact of FoxP3+ regulatory $T$ cells in relation to $\mathrm{CD} 8+\mathrm{T}$ lymphocyte density in human colon carcinomas. PLoS One. 2012;7:e42274.

178. Saito T, Nishikawa H, Wada H, Nagano Y, Sugiyama D, Atarashi K, et al. Two FOXP3+CD4+ T cell subpopulations distinctly control the prognosis of colorectal cancers. Nat Med. 2016;22:679-84 
179. Ouyang W, Beckett O, Ma Q, Paik J, DePinho RA, Li MO. Foxo proteins cooperatively control the differentiation of Foxp3+ regulatory T cells. Nat Immunol. 2010;11:618-27.

180. Josefowicz SZ, Lu L-F, Rudensky AY. Regulatory T cells: mechanisms of differentiation and function. Annu Rev Immunol. 2012;30:531-64.

181. Lu L, Barbi J, Pan F. The regulation of immune tolerance by FOXP3. Nat Rev Immunol. 2017;17:703-17.

182. Zheng Y, Josefowicz SZ, Kas A, Chu T-T, Gavin MA, Rudensky AY. Genomewide analysis of Foxp3 target genes in developing and mature regulatory $T$ cells. Nature. 2007;445:936-40.

183. Rudra D, DeRoos P, Chaudhry A, Niec RE, Arvey A, Samstein RM, et al. Transcription factor Foxp3 and its protein partners form a complex regulatory network. Nat Immunol. 2012;13:1010-9.

184. Hori S. The Foxp3 interactome: a network perspective of T(reg) cells. Nat Immunol. 2012:13:943-5.

185. Cui Y-M, Jiao H-L, Ye Y-P, Chen C-M, Wang J-X, Tang N, et al. FOXC2 promotes colorectal cancer metastasis by directly targeting MET. Oncogene. 2015;34:4379-90

186. Li Q, Wu J, Wei $P, X u$ Y, Zhuo C, Wang Y, et al. Overexpression of forkhead Box C2 promotes tumor metastasis and indicates poor prognosis in colon cancer via regulating epithelial-mesenchymal transition. Am J Cancer Res. 2015;5:2022-34.

187. Liu J, Zhang Z, Li X, Chen J, Wang G, Tian Z, et al. Forkhead box C1 promotes colorectal cancer metastasis through transactivating ITGA7 and FGFR4 expression. Oncogene. 2018;37:5477-91.

188. Qiao Y, Jiang X, Lee ST, Karuturi RKM, Hooi SC, Yu Q. FOXQ1 regulates epithelial-mesenchymal transition in human cancers. Cancer Res. 2011;71: 3076-86.

189. Li Y, Zhang Y, Yao Z, Li S, Yin Z, Xu M. Forkhead box Q1: a key player in the pathogenesis of tumors (review). Int J Oncol. 2016:49:51-8.

190. Kaneda H, Arao T, Tanaka K, Tamura D, Aomatsu K, Kudo K, et al. FOXQ1 is overexpressed in colorectal cancer and enhances tumorigenicity and tumor growth. Cancer Res. 2010;70:2053-63.

191. Christensen J, Bentz S, Sengstag T, Shastri VP, Anderle P. FOXQ1, a novel target of the Wnt pathway and a new marker for activation of Wnt signaling in solid tumors. PLoS One. 2013:8:e60051 Samant R, editor.

192. Peng X, Luo Z, Kang Q, Deng D, Wang Q, Peng H, et al. FOXQ1 mediates the crosstalk between TGF- $\beta$ and Wnt signaling pathways in the progression of colorectal cancer. Cancer Biol Ther. 2015;16:1099-109.

193. Lu S-Q, Qiu Y, Dai W-J, Zhang X-Y. FOXR2 promotes the proliferation, invasion, and epithelial-mesenchymal transition in human colorectal Cancer cells. Oncol Res. 2017;25:681-9.

194. Quintero-Ronderos P, Laissue P. The multisystemic functions of FOXD1 in development and disease. J Mol Med. 2018;96:725-39.

195. Han T, Lin J, Wang Y, Fan Q, Sun H, Tao Y, et al. Forkhead box D1 promotes proliferation and suppresses apoptosis via regulating polo-like kinase 2 in colorectal cancer. Biomed Pharmacother. 2018;103:1369-75.

196. Huang $X$, Xiang L, Li Y, Zhao Y, Zhu H, Xiao Y, et al. Snail/FOXK1/Cyr61 signaling axis regulates the epithelial-mesenchymal transition and metastasis in colorectal cancer. Cell Physiol Biochem. 2018:47:590-603.

197. Lo P-K, Lee JS, Sukumar S. The p53-p21WAF1 checkpoint pathway plays a protective role in preventing DNA rereplication induced by abrogation of FOXF1 function. Cell Signal. 2012;24:316-24.

198. Ma W, Jiang J, Li M, Wang H, Zhang $H$, He X, et al. The clinical significance of forkhead box protein $\mathrm{A} 1$ and its role in colorectal cancer. Mol Med Rep. 2016;14:2625-31.

199. He GY, Hu JL, Zhou L, Zhu XH, Xin SN, Zhang D, et al. The FOXD3/miR-214/ MED19 axis suppresses tumour growth and metastasis in human colorectal cancer. Br J Cancer. 2016;115:1367-78.

200. Wu M, Wang J, Tang W, Zhan X, Li Y, Peng Y, et al. FOXK1 interaction with $\mathrm{FHL} 2$ promotes proliferation, invasion and metastasis in colorectal cancer. Oncogene. 2016;5:e271.

201. Wu Y, Peng Y, Wu M, Zhang W, Zhang M, Xie R, et al. Oncogene FOXK1 enhances invasion of colorectal carcinoma by inducing epithelialmesenchymal transition. Oncotarget. 2016;7:51150-62.

202. Wu Y, Xie R, Liu X, Wang J, Peng Y, Tang W, et al. Knockdown of FOXK1 alone or in combination with apoptosis-inducing 5-FU inhibits cell growth in colorectal cancer. Oncol Rep. 2016;36:2151-9.

203. Li K, Guo Q, Yang J, Chen H, Hu K, Zhao J, et al. FOXD3 is a tumor suppressor of colon cancer by inhibiting EGFR-Ras-Raf-MEK-ERK signal pathway. Oncotarget. 2017;8:5048-56.
204. Qian Y, Xia S, Feng Z. Sox9 mediated transcriptional activation of FOXK2 is critical for colorectal cancer cells proliferation. Biochem Biophys Res Commun. 2017;483:475-81.

205. Nik AM, Reyahi A, Pontén F, Carlsson P. Foxf2 in intestinal fibroblasts reduces numbers of Lgr5+ stem cells and adenoma formation by inhibiting Wnt signaling. Gastroenterology. 2013;144:1001-11.

206. Melotte V, Yi JM, Lentjes MHFM, Smits KM, Van Neste L, Niessen HEC, et al. Spectrin repeat containing nuclear envelope 1 and forkhead box protein E1 are promising markers for the detection of colorectal cancer in blood. Cancer Prev Res. 2015;8:157-64.

207. Sugimachi K, Matsumura T, Shimamura T, Hirata H, Uchi R, Ueda M, et al. Aberrant methylation of FOXE1 contributes to a poor prognosis for patients with colorectal cancer. Ann Surg Oncol. 2016;23:3948-55.

208. Ma W, Yu Q, Jiang J, Du X, Huang L, Zhao L, et al. miR-517a is an independent prognostic marker and contributes to cell migration and invasion in human colorectal cancer. Oncol Lett. 2016;11:2583-9.

209. Chen W, Tong K, Yu J. MicroRNA-130a is upregulated in colorectal cancer and promotes cell growth and motility by directly targeting forkhead box F2. Mol Med Rep. 2017;16:5241-8.

210. Dai Y, Wang M, Wu H, Xiao M, Liu H, Zhang D. Loss of FOXN3 in colon cancer activates beta-catenin/TCF signaling and promotes the growth and migration of cancer cells. Oncotarget. 2017:8:9783-93.

211. Yang J-Y, Hung M-C. A new fork for clinical application: targeting forkhead transcription factors in Cancer. Clin Cancer Res. 2009:15:752-7.

212. Yeh JE, Toniolo PA, Frank DA. Targeting transcription factors. Curr Opin Oncol. 2013:25:652-8.

213. Gayvert KM, Dardenne E, Cheung C, Boland MR, Lorberbaum T, Wanjala J, et al. A computational drug repositioning approach for targeting oncogenic transcription factors. Cell Rep. 2016;15:2348-56.

214. Lambert M, Jambon S, Depauw S, David-Cordonnier M-H. Targeting transcription factors for cancer treatment. Molecules. 2018;23:1479.

215. Liu X, Cai X, Hu B, Mei Z, Zhang D, Ouyang G, et al. Forkhead transcription factor 3a (FOXO3a) modulates hypoxia signaling via up-regulation of the von Hippel-Lindau gene (VHL). J Biol Chem. 2016;291:25692-705.

216. Okada M, Kanamori M, Someya K, Nakatsukasa H, Yoshimura A. Stabilization of Foxp3 expression by CRISPR-dCas9-based epigenome editing in mouse primary T cells. Epigenetics Chromatin. 2017:10:24

\section{Ready to submit your research? Choose BMC and benefit from:}

- fast, convenient online submission

- thorough peer review by experienced researchers in your field

- rapid publication on acceptance

- support for research data, including large and complex data types

- gold Open Access which fosters wider collaboration and increased citations

- maximum visibility for your research: over $100 \mathrm{M}$ website views per year

At BMC, research is always in progress.

Learn more biomedcentral.com/submission 